\title{
Annotations
}

\section{Screening for squint and poor vision}

Screening, the economical method of detecting disease before symptoms occur, does not carry with it the stimulating cachet of technological medicine; when one considers that a substantial proportion of visual defects in children are preventable, however, the importance of screening of vision begins to take on a new light. Preventable visual defects in childhood include those caused by congenital cataracts, congenital glaucoma, bilateral high ametropia, retinoblastoma, and possibly, retrolental fibroplasia. Congenital cataract is by far the largest preventable cause of bilateral visual defects. In addition to this, a relatively small number (about $4 \%$ of the population), have amblyopia secondary to refractive error or squint. These cases are almost invariably unilateral.

What constitutes a visual handicap? Any bilateral untreatable visual defect gives rise to visual handicap of varying degree. For screening, the real question is whether unilateral amblyopia results in a handicap sufficient to make screening economically or socially worthwhile. The risk of injury to the nonamblyopic eye is about $1 \cdot 75 / 1000$ amblyopic subjects

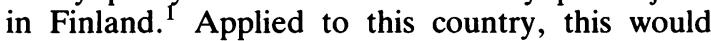
mean that there are about 2000 people (or 25 each year) blinded in this way. Amblyopia is often detected by parents who notice the associated squint, and only a proportion are likely to be detected before symptoms occur.

\section{What test are currently used?}

The tester usually takes a history of the parents' observations and a family history; he will carry out an external inspection, look at the corneal reflections of a light to see if they are symmetrical, and carry out a cover test. ${ }^{2}$ An orthoptist will carry out additional tests to detect abnormalities of binocular vision. If a doctor is doing the testing, an ophthalmoscope will be used to detect abnormalities of the refractive media: only rarely is refraction part of screening.

\section{When do we carry out these tests?}

Every baby has a neonatal test and this is followed, with regional variations, by tests at 6 weeks, 8 months, 18-21 months, and 3 to $3 \frac{1}{2}$ years by the general practitioner, community paediatrician, or a health visitor; and, in a few regions, a community orthoptist will carry out screening tests at some stage. In principle, this scheme provides an adequate screening programme, but one which is often flawed, for the following reasons.

The tests may be carried out at the wrong time. The $3 \frac{1}{2}$ year test probably detects an inadequate proportion of visual defects and detects many amblyopic children too late for optimal treatment. ${ }^{3}$ The neonatal test is good but should be modified by paediatricians to detect errors of the refractive media. ${ }^{4}$ A 6 week test is also timely, but external inspection alone is not likely to detect amblyopia or squint at this age when the child does not yet have good fixation. The test at 8-9 months that is currently carried out should be replaced by a test between 3 and 6 months which is a better time to treat bilateral diseases, especially congenital cataract. The 18-21 month test should probably be replaced by one at 1 year and possibly one at 2 years, followed by a preschool and biannual school test.

The present tests do not detect disease accurately and are poorly performed. The neonatal test and the tests in infancy should be modified to detect errors in the refractive media. ${ }^{4}$ If $a$ bright direct ophthalmoscope is held about 18 inches away from a neonate's eye, with the observer looking down the beam of light from the ophthalmoscope into the eye, a bright red reflex is normally seen in fair haired children and a dark red or greyish reflex in brown or black skinned children. Anything which prevents this reflex from being seen by the observer should be interpreted as an abnormality in the refractive media, and these children need to be referred to an ophthalmologist without delay. Every child should be examined in this way as part of the neonatal test.

The standard of testing is often poor with too many false positive and false negative results. Couldn't orthoptists put their undoubted skills to better use in training than in testing?

The tests should be modified, especially in the older age groups, to simplify the procedures. For instance, the use of a stereogram, ${ }^{5}$ a more widespread use of the Sheridan Gardiner, or other figure matching or naming techniques, may also be helpful.

The taking of a brief family history and listening to the parents' observations would improve selection and help to develop an 'at risk' concept. 


\section{What happens to the screened children?}

If they are abnormal, especially if below 3 years of age, they are usually referred to an ophthalmologist. Older than 3 years, they are usually referred to an optician or an ophthalmic medical practitioner (a doctor who refracts and works in a medical eye centre). If the problem is non-refractive, children should be referred to an ophthalmologist. The outstanding problem is that if any changes in screening were to result in larger numbers of referrals, an already overstretched system would be swamped.

\section{What if we want an 'ideal' system?}

If we are primarily screening for amblyopia we must remember that only a small number of people will be prevented from going blind each year and, therefore, the cost implications of screening are paramount. It would be possible to increase the number of orthoptists screening younger children. As refractive error is the greatest predictor of amblyopia ${ }^{6}$ it is essential that orthoptists should be well versed in the simple art of refraction: for almost unaccountable reasons they are not currently trained in this technique. Orthoptists, who are superbly trained in the handling of young children, would be able to carry out tests on selected children to determine their acuity, using methods such as forced preferential looking.

Photo refraction is an exciting technique under development that may be used by less fully trained personnel to detect refractive errors. There are difficulties with this in that techniques requiring a camera are expensive if Polaroid film is used, complicated if black and white film is used, and the capital cost of video photo refraction is high Another problem is that the degree of training required probably means that the skills of an orthoptist are necessary. We should develop an 'at risk' concept for children with a family history, a history of squint, or refractive error.

It is difficult to be clear about the role of opticians in screening of vision. The use of opticians for this is likely to be very expensive and to result in little reduction in visual handicap, but it is possible to see a role for them as the first point of referral after screening for the management of most refractive errors.

Interest is stirring among professional bodies and those concerned with community health and we can hope for a bright future in screening. This must be preceded, however, by careful nationwide planning, or we may be involved in enormous expenditure for little gain, which might never be rectified.

\section{References}

1 Tommila V, Tarkkanen A. Incidence of loss of vision in the healthy eye in amblyopia. $\mathrm{Br}$ J Ophthalmol 1981;65:575-7.

2 Harcourt RB. Detection and management of squint. Arch Dis Child 1983;58:675-6.

3 Ingram RM, Holland WW, Walker C, Wilson JM, Arnold PE, Dally S. Screening for visual defects in preschool children. $\mathrm{Br} J$ Ophthalmol 1986;70:16-21.

4 Taylor D. Screening? Trans Ophthalmol Soc UK 1986;104: 16-21.

${ }^{5}$ Hammond RS, Schmidt PP. A random dot E stereogram for the vision screening of children. Arch Ophthalmol 1986;104:54-60.

${ }^{6}$ Ingram RM, Walker C, Wilson JM, Arnold PE, Dally S. Prediction of amblyopia and squint by means of refraction at age one year. Br J Ophthalmol 1986;70:12-16.

DAVID TAYloR Hospital for Sick Children, Great Ormond Street, London WC1N $3 \mathrm{JH}$ 